\title{
Perkütan Nefrolitotomi: 2300 Vaka ile Tek Merkez Sonuçlarımız
}

\section{Percutaneous Nephrolithotomy: Our Results of a Single-Centre Analysis in 2300 Cases}

\author{
Akif Erbin, Yalçın Berberoğlu, Ömer Sarılar, Mehmet Fatih Akbulut, Faruk Özgör, \\ Erkan Sönmezay, Abdulmuttalip Şimşek, Zafer Gökhan Gürbüz \\ Haseki Eğitim ve Araştırma Hastanesi, Üroloji Kliniği, İstanbul, Türkiye
}

Özet

\begin{abstract}
Amaç: Çalışmamızda 11 yıllık süreçte 2300 vakada uyguladığımız perkütan nefrolitotomi (PNL) operasyonlarının sonuçları değerlendirilmiştir.

Yöntemler: Kliniğimizde Mart 2002-Nisan 2013 yılları arasında toplam 2300 PNL operasyonu uygulandı. Hastaların demografik özellikleri (yaş, cinsiyet, vücut kitle indeksi), taş özellikleri (taraf, boyut, lokalizasyon), üriner sistem özellikleri (böbrek anomalisi, geçirilmiş cerrahi, geçirilmiş beden dışı şok dalga tedavisi), operasyon parametreleri (operasyon süresi, skopi süresi, giriş sayısı, giriş yeri, transfüzyon, komplikasyon), operasyon sonrası bulguları (hastanede kalış süresi, transfüzyon, komplikasyon, taşsızlık) hazırlanan PNL formlarına kaydedildi. Veriler geriye dönük olarak değerlendirildi.
\end{abstract}

Bulgular: PNL operasyonlarının 1225'i (\%53.2) sol taraflı, 1074'ü (\%46.6) sağ taraflı, 1'i ise bilateral olarak uygulandı. Ortalama yaş 43.5 (7-83) ve ortalama VKi $26,6 \mathrm{~kg} / \mathrm{m}^{2}(12-51)$ idi. Toplam 46 (\%2) vakada PNL uygulanan tarafta böbrek anomalisi mevcuttu. Bunların 16'sı atnalı böbrek anomalisi idi. Vakaların \%18.6'sınde birden fazla giriş uygulanırken, \%9.8'inde interkostal giriş uygulandı. Operasyon içi ve operasyon sonrası transfüzyon oranları sırası ile \%1.4 ve \%2.9 idi. Ortalama taş boyutu $7.5 \pm 4.1 \mathrm{~cm}^{2}$ olarak hesaplandı. Tam taşsızlık (SF) oranı \%65.1 iken, genel başarı oranı ise \%78.5 idi.

Sonuç: Artan deneyim ve endoürolojideki gelişmeler sayesinde PNL, tüm dünyada olduğu gibi ülkemizde de düşük morbidite ve yüksek başarı ile yaygın bir şekilde uygulanmaktadır. (Haseki Tıp Bülteni 2014; 52: 19-24)

Anahtar Sözcükler: Böbrek taşı, böbrek anomalisi, perkütan nefrolitotomi
Abstract

Aim: In this study, we evaluated the results of 2300 patients who underwent percutaneous nephrolithotomy (PNL) between March 2002 and April 2013.

Methods: In our clinic, a total of 2300 PNL operations were performed between March 2002 - April 2013. Demographic characteristics (age, gender), body mass index, stone features (side, size, location), clinical characteristics of the urinary tract (renal anomaly, previous surgery, previous extracorporeal shock wave lithotripsy), operation parameters (duration of the intervention and fluoroscopy, number of access, location of access, transfusion, complications), post-operative data (length of hospital stay, transfusion, complications, stone-free) were recorded on PNL forms. The data were analyzed retrospectively.

Results: Of all the PNL operations, 1225 (53.2\%) were left-sided, 1074 (46.6\%) were right-sided and 1 was bilateral. The mean age of the subjects was 43.5 (7-83) years and the mean body mass index was $26.6 \mathrm{~kg} / \mathrm{m} 2(12-51)$. A total of 46 (2\%) cases had renal anomalies. There were 16 patients with horseshoe kidney. More than one accesses was performed in $18.6 \%$ of the patient and intercostal access was done in $9.8 \%$. Perioperative and postoperative transfusion rates were $1.4 \%$ and $2.9 \%$, respectively. The mean stone size was $7.5 \pm 4.1 \mathrm{~cm}^{2}$. Stone-free (SF) rate was $65.1 \%$ and success rate was $78.5 \%$.

Conclusion: With increasing experience and advances in endourology, PNL is being widely performed with low morbidity and high success in our country as in the world. (The Medical Bulletin of Haseki 2013; 51: 19-24)

Key words: Kidney stone, renal anomaly, percutaneous nephrolithotomy
Yazışma Adresi/Address for Correspondence: Akif Erbin

Haseki Eğitim ve Araştırma Hastanesi, Üroloji Kliniği, İstanbul, Türkiye

E-posta: akiferbin@hotmail.com

Geliş Tarihi/Received: 25 Haziran 2013 Kabul Tarihi/Accepted: 12 Ağustos 2013 published by Galenos Publishing. 


\section{Giriş}

İlkolarakM.Ö. 4800'lüyıllarda belgelerine rastladığımız üriner sistem taş hastalığı insanoğlunu etkileyen en eski hastalıklardan birisidir. Günlük üroloji pratiğimizde üriner enfeksiyonlar ve prostat hastalıklarından sonra üçüncü en sık karşılaştı̆̆ımız patolojidir

Amerika Birleşik Devletleri'nde 2007 yılında yapılan bir çalışmada, bir insanın hayatı boyunca üriner sistem taş hastalığı ile karşılaşma intimalinin \%10-\%15 olduğu bildirilmiştir (1). Ülkemizde 2011 yllında yapılan güncel çalışmada taş prevelansının \%11.1 olduğu tespit edimiş ve ülkemizin endemik ülkeler arasında olduğu vurgulanmıştır (2).

Üriner sistem taş hastalığında tedavi seçenekleri arasında beden dışı şok dalga tedavisi (ESWL), perkütan nefrolitotomi (PNL), üreterorenoskopi (URS), retrograd intrarenal cerrahi (RIRS), laparoskopik cerrahi, açık cerrahi ve kombinasyon tedavileri yer almaktadır. ESWL'nin 1980'lerin başında kullanıma girmesi ve endoüroloji alanındaki gelişmeler sayesinde taş hastalığı tedavisinde son 30 yıl içerisinde büyük değişimler yaşanmıştır. Bu değişimler son yıllarda RIRS ve perkütan cerrahideki gelişmeler ile hızla devam etmiştir. Tüm bunların neticesinde, güncel üroloji pratiğinde açık cerrahiye olan gereksinim \%0.7-\%4'lere kadar düşmüş ve büyük böbrek taşlarının tedavisinde PNL ilk seçenek olarak yerini almıştır (3).

Çalışmamızda ilk olarak 2002'de uygulamaya başladığımız ve 11 yıllık süreçte toplam 2300 vakada gerçekleştirdiğimiz PNL operasyonlarının sonuçlarını sunmayı amaçladık.

\section{Yöntemler}

\section{Çalışma Dizaynı}

Çalışmaya Mart 2002-Nisan 2013 yılları arasında kliniğimizde yapılan 2300 PNL vakası dahil edildi. Uygulanan her vaka için hastaların demografik özellikleri (yaş, cinsiyet, vücut kitle indeksi [VKi]), taş özellikleri (taraf, boyut, lokalizasyon), üriner sistem özellikleri (böbrek anomalisi, geçirilmiş cerrahi, geçirilmiş ESWL), operasyon parametreleri (operasyon süresi, skopi süresi, giriş sayısı, giriş yeri, transfüzyon, komplikasyon), operasyon sonrası bulguları (hastanede kalış süresi, transfüzyon, komplikasyon, taşsızlık) hazırlanan PNL formlarına kaydedildi. Veriler Microsoft ${ }^{\circledR}$ Excel programı yardımı ile toplanıp geriye dönük olarak değerlendirildi.

\section{Operasyon Öncesi Değerlendirme}

Operasyon öncesi tüm hastalar bilgilendirilmiş onam formunu imzaladılar. Tüm hastalar operasyon öncesinde tam kan sayımı, böbrek fonksiyon testleri
(BUN, kreatinin), serum elektrolit değerleri, karaciğer fonksiyon testleri (ALT, AST), kanama ve pıhtılaşma testleri (kanama zamanı, pıhtılaşma zamanı, aPTT, PT, INR), seroloji testleri (HbsAg, Anti- HCV, Anti-HIV) ve açlık kan şekeri ile değerlendirildi. Tüm hastalara işlemden bir hafta önce idrar kültürü yapıldı ve gereken durumlarda uygun antibiyoterapi tedavisi düzenlendi. Antibiyotik profilaksi olarak operasyon sabahı (3). kuşak sefalosporin ya da kinolon kullanıldı ve profilaksiye nefrostomi kateteri alınıncaya kadar devam edildi. Hastaların operasyondan 7-10 gün öncesinde kullandıkları antikoagülan ya da antiagregan ilaçları kesildi ve endike olan hastalara düşük molekül ağırlıklı heparin tedavisi başlandı.

Tüm hastalar operasyon öncesinde taş ve diğer üriner sistem patolojileri açısından IVP (intravenöz piyelografi) ve/veya kontrassı BT ile değerlendirildi. Opak taşı olan hastalara operasyon sabahı tekrar DÜSG (düz üriner sistem grafisi) çekildi. Taş yüzey alanı güncel EAU (European Association of Urology) taş kılavuzunda önerilen şekilde, taşın en uzun çapı ve bunu dik kesen çapın çarpılması ile $\mathrm{cm}^{2}$ cinsinden hesaplandı. Birden fazla taş olması durumunda her taş için ayrı ayrı hesaplanıp toplam taş yükü baz alındı.

\section{PNL Tekniği}

Hastaya endoüroloji masasında (Modularis Uro, Siemens) genel anestezi uygulanmasını takiben litotomi pozisyonu verildi. PNL uygulanacak tarafa C-kollu floroskopi (Sire Mobil Compact, Siemens) altında sistoskopi yardımı ile $5 \mathrm{~F}$ üreter katateri yerleştirildi. Üreter kataterinin geçmesinde zorlanıldığı durumlarda $9.5 \mathrm{~F}$ Rijit URS ile üreterorenoskopi yapılarak üreter kateteri yerleştirildi. Mesaneye $16 \mathrm{~F}$ üretral katater tatbiki sonrası, üreter katateri üretral katatere ipek sütür ile tespit edildi. Daha sonra hasta yüzükoyun pozisyonuna getirildi. Bu pozisyonda hastanın her iki yan tarafı ve göğüs bölgesi silikon yastıklarla desteklendi. Operasyon bölgesinin antiseptik solüsyon ile silinmesini ve steril örtü seti ile hastanın örtülmesini takiben floroskopi rehberliğinde perkütan erişim iğnesi (18G Percutaneous Access Needle, Boston Scientific Corporation, Natick MA) ile uygun kalikse giriş gerçekleştirildi. İ̆ne içerisinden gönderilen kılavuz tel (SensorTM Guide Wire, Boston Scientific) üzerinden yüksek basınçlı balon dilatatör (NephroMaxTM Microvasive High Pressure Balloon Catheter, Boston Scientific) ile kanal genişletildi ve $30 \mathrm{Fr}$ çalışma kılıfı (Amplatz sheat, Boston Scientific) yerleştirildi. Balon dilatasyon seti olmadığı nadir durumlarda ise Amplatz dilatatör seti (Amplatz Renal Dilator Set, Cook Medical) kullanıldı. Nefroskopi 26 F rijit nefroskop ile yapıldı. Taşlar ultrasonik taş kırıcı (Swiss Lithoclast ${ }^{\circledR}$, EMS, Nyon, 
Switzerland) yardımı ile parçalanarak 3 bacaklı taş forsepsi ya da basket kateter (Perc-N Circle, Cook Medikal) ile dışarı alındı. Drenaj için renal pelvise ya da uygun kalikse 14 F nefrostomi tüpü (Malecot Nephrostomy Catheter, Cook Medical) yerleştirildi. Gerekli olduğu durumlarda ek girişler aynı seansta yapıldı.

\section{Operasyon Sonrası Değerlendirme}

Operasyon sonrası ilk gün tüm hastalar DÜSG çekilerek taş temizliği açısından değerlendirildi. Tam taşsızlık (SF) ya da klinik önemsiz rezidüel parçacık (CIRF) sağlanan, ateşi ve kanaması olmayan hastaların 2. gün çekilen antegrad nefrostografide üreterlerin mesaneye kadar açık olduğu görüldükten sonra nefrostomi tüpleri çekildi. 48 saatten uzun süren uzamış idrar kaçağı durumunda çift J üreter kateteri takıldı. Gerekli durumlarda tekrar PNL, URS ve ESWL ek tedavi seçenekleri olarak değerlendirildi. Tüm hastalar operasyon sonrası 3. ayda IVU ya da BT ile değerlendirildi. Dört $\mathrm{mm}$ 'den küçük, semptoma, tıkanıklığa ve enfeksiyona neden olmayan rezidüel parçacıklar CIRF, 4 mm'den büyük parçacıklar ise REST olarak kabul edildi. SF ya da CIRF elde edildiği durumlarda PNL işlemi 'başarılı' olarak kabul edildi.

\section{Bulgular}

Çalışmaya 2153 hastada uygulanan toplam $2300 \mathrm{PNL}$ vakası alındı. Hastaların demografik özellikleri Tablo 1'de özetlenmektedir. Vakaların \%58'ini erkekler, \%52'sini kadınlar oluşturmakta idi. Vakaların \%3'ü 18 yaş altı, $\% 92.6$ 'sı 18-70 yaş arası ve \%4.3'ü 70 yaşın üzerinde idi. Ortalama yaş 43.5 (7-83) idi. Ortalama VKi 26.6 (1251) olmakla birlikte, $12(\% 0.5)$ hastada morbid obezite mevcuttu.

PNL operasyonlarının 1225'i (\%53.2) sol taraflı, 1074'ü (\%46.6) sağ taraflı, 1 'i ise bilateral olarak uygulandı. Toplam 2300 vakanın $475^{\prime}$ inde (\%20.6) aynı tarafta en az bir cerrahi anamnezi; 518'inde (\%22.5) ise aynı tarafta en az bir seans ESWL anamnezi mevcuttu. Toplam 46 (\%2) vaka PNL uygulanan tarafta böbrek anomalisine sahipti. Bunların 16'sını atnalı böbrek anomalisi oluşturmakta idi. Vakaların 17'sinde ise diğer tarafın hipoplazik, fonksiyonsuz ya da nefrektomize oluşuna bağlı soliter böbrek durumu mevcuttu (Tablo 2).

Vakaların taş karakteristikleri ve taşsızlık oranları Tablo 3'te özetlenmektedir. Taşların \%9.1'i komplet koraliform, $\% 5.4$ 'ü parsiyel koraliform, \%26.7'si pelvis ve alt kaliks, $\% 15.6$ 'sı pelvis ve multipl kaliks, \%3.9'u multipl kaliks, $\% 17.9^{\prime}$ u izole pelvis, $\% 16^{\prime}$ sı izole alt kaliks, \%1.5'i izole orta kaliks, \%3.3'ü izole üst kaliks, \%0.3'ü izole kaliksiyel divertikül ve $\% 0.2$ 'si proksimal üreter yerleşimli idi. Ortalama taş boyutu $7.5 \pm 4.1 \mathrm{~cm}^{2}$ olarak hesaplandı.
Toplam 2300 vakada SF oranı \%65.1 iken, SF ve CIRF toplamı olarak hesaplanan genel başarı oranı ise $\% 78.5$ idi.

Toplam 2300 vakanın 227'sinde (\%9.8) interkostal giriş uygulandı. Bunların 225'inde 11-12. kot aralığı, 2'sinde ise 10-11. kot aralığı kullanıldı. Vakaların 428'inde (\%18.6) birden fazla giriş uygulandı. Operasyon sonunda genellikle $14 \mathrm{Fr}$ nefrostomi tüpü yerleştirilirken, 25 vaka ise tüpsüz olarak uygulandı. Bunların 20'si subtotal tüpsüz, 5'i ise total tüpsüz olarak gerçekleştirildi. Vakaların ortalama operasyon süresi $65 \pm 27.7 \mathrm{dk}$, ortalama skopi süresi $8.4 \pm 5.3 \mathrm{dk}$ ve ortalama hastanede kalış süresi $3.0 \pm 1.7$ gün idi.

Operasyon sırasında ve operasyon sonrasında gelişen komplikasyonlar Tablo 4'te özetlenmektedir. Genel komplikasyon oranı \%29.5 olarak hesaplandı. Komplikasyonlar arasında en sık görüleni kanama idi. Toplam 2300 vakanın 377'sinde (\%16.3) kanama görülürken, transfüzyon gerektiren kanama oranları sırası ile operasyon içi ve operasyon sonrası \%1.4 ve \%2.9 idi. Operasyon sonrası dönemde arteriyovenöz fistül ya da psödoanevrizmadan kaynaklanan yoğun kanama nedeni ile 10 hastaya anjiyo-embolizasyon uygulandı. Bu vakaların 2'sinde kanama devam etmesi nedeniyle üzerine açık operasyon yapıldı. Operasyon sonrası ateş $66(\% 2.8)$ vakada, sepsis ise $16(\% 0.7)$ vakada görüldü.

\begin{tabular}{|l|c|}
\hline \multicolumn{2}{|l|}{ Tablo 1. Demografik özellikler } \\
\hline & Sayı/Oran \\
\hline Erkek/ kadın & $1335(\% 58) / 965(\% 52)$ \\
\hline Yaş (yıl) & \\
$\mathbf{1 8 <}$ & $70(\% 3)$ \\
$\mathbf{1 8 - 7 0}$ & $2130(\% 92.6)$ \\
$\mathbf{7 0 \geq}$ & $100(\% 4.3)$ \\
Ortalama & $43.5(7-83)$ \\
\hline VKi (kg/m $\mathbf{2})$ & \\
$\mathbf{3 0 <}$ & $1930(\% 84)$ \\
$\mathbf{3 0 - 4 5}$ (obez) & $358(\% 15.5)$ \\
$\mathbf{4 5 >}$ (morbid obez) & $12(\% 0.5)$ \\
Ortalama & $26.6(12-51)$ \\
\hline
\end{tabular}

\begin{tabular}{|l|l|}
\hline \multicolumn{2}{|l|}{ Tablo 2. Üriner sistem özellikleri } \\
\hline $\begin{array}{l}\text { Böbrek anomalisi } \\
\text { Atnalı böbrek }\end{array}$ & 16 \\
$\quad$ Çift sistem & 17 \\
Rotasyon anomalisi & 13 \\
$\quad$ Toplam & $46(\% 2)$ \\
\hline Soliter böbrek & 17 \\
\hline Aynı taraf cerrahi anamnezi & \\
Primer & $1825(\% 79.4)$ \\
Sekonder & $434(\% 18.9)$ \\
Tersiyer & $41(\% 1.7)$ \\
\hline ESWL anamnezi & $518(\% 22.5)$ \\
\hline
\end{tabular}


Tablo 3. Taş karakteristikleri ve taşsızlık oranları

\begin{tabular}{|l|c|c|c|c|c|}
\hline Taş karakteristikleri & $\mathbf{N}$ & Ort. boyut (cm $) \pm S T D$ & SF & CIRF & REST \\
\hline Komplet koraliform & $210(\% 9.1)$ & $16.8 \pm 8.3$ & $93(\% 44.3)$ & $28(\% 13.3)$ & $89(\% 42.4)$ \\
\hline Parsiyel koraliform & $125(\% 5.4)$ & $11.6 \pm 5.8$ & $57(\% 45.6)$ & $24(\% 14.2)$ & $44(\% 35.2)$ \\
\hline Pelvis ve alt kaliks & $614(\% 26.7)$ & $7.4 \pm 3.8$ & $422(\% 68.7)$ & $91(\% 14.8)$ & $101(\% 16.4)$ \\
\hline Pelvis ve multipl kaliks & $359(\% 15.6)$ & $9.4 \pm 5.6$ & $147(\% 40.9)$ & $65(\% 18.1)$ & $147(\% 40.9)$ \\
\hline Multipl kaliks & $89(\% 3.9)$ & $5.5 \pm 2.9$ & $44(\% 49.4)$ & $16(\% 18)$ & $29(\% 32.6)$ \\
\hline İzole pelvis & $411(\% 17.9)$ & $5.8 \pm 3.3$ & $352(\% 85.6)$ & $23(\% 5.6)$ & $36(\% 8.8)$ \\
\hline Izole alt kaliks & $369(\% 16)$ & $4.2 \pm 2.5$ & $296(\% 80.2)$ & $43(\% 11.7)$ & $30(\% 8.1)$ \\
\hline İzole orta kaliks & $35(\% 1.5)$ & $4.0 \pm 3.1$ & $29(\% 82.9)$ & $2(\% 5.7)$ & $4(\% 11.4)$ \\
\hline İzole üst kaliks & $76(\% 3.3)$ & $5.7 \pm 3.4$ & $51(\% 67.1)$ & $12(\% 15.8)$ & $13(\% 17.1)$ \\
\hline İzole divertikül & $8(\% 0.3)$ & $8.0 \pm 5.2$ & $5(\% 62.5)$ & $2(\% 25)$ & $1(\% 12.5)$ \\
\hline Proksimal üreter & $4(\% 0.2)$ & $4.0 \pm 1.4$ & $2(\% 50)$ & $1(\% 25)$ & $1(\% 25)$ \\
\hline Toplam & 2300 & $7.5 \pm 4.1$ & $1498(\% 65.1)$ & $307(\% 13.4)$ & $495(\% 21.5)$ \\
\hline
\end{tabular}

Tablo 4. Komplikasyonların sınıflandırıması

\begin{tabular}{|c|c|}
\hline $\begin{array}{l}\text { Kanama } \\
\quad \text { Transfüzyon gerektiren kanama }\end{array}$ & $\begin{array}{l}377(\% 16.3) \\
101(\% 4.3)\end{array}$ \\
\hline $\begin{array}{l}\text { Ateş }(>38.5 \text { oC) } \\
\text { Sepsis }\end{array}$ & $\begin{array}{l}66(\% 2.8) \\
16(\% 0.7)\end{array}$ \\
\hline Uzamış drenaj & $141(\% 6)$ \\
\hline PKS perforasyonu & $56(\% 2.4)$ \\
\hline $\begin{array}{l}\text { Akciğer ile ilgili komplikasyonlar } \\
\text { Hemotoraks } \\
\text { Hidrotoraks } \\
\text { Pnömotoraks } \\
\text { Reno-plevral fistül }\end{array}$ & $\begin{array}{l}29(\% 1.2) \\
14(\% 0.61) \\
12(\% 0.52) \\
2(\% 0.09) \\
1(\% 0.04)\end{array}$ \\
\hline Kardiak komplikasyonlar & $6(\% 0.26)$ \\
\hline Kolon perforasyonu & $2(\% 0.09)$ \\
\hline $\begin{array}{l}\text { Açık operasyon } \\
\text { Primer onarım } \\
\text { Nefrektomi }\end{array}$ & $\begin{array}{l}10(\% 0.43) \\
5(\% 0.22) \\
5(\% 0.22)\end{array}$ \\
\hline Ölüm & $2(\% 0.09)$ \\
\hline
\end{tabular}

Vakaların \%6'sına uzamış idrar drenajı nedeni ile çift J stent uygulandı. Operasyon sonrası çeşitli nedenlerden (uzamış drenaj, PKS ekstravazasyonu, üreter obstrüksiyonu) dolayı toplam çift J stent uygulanma oranı ise \%7.1 olarak tespit edildi.

Toplam 29 (\%1.2) vakada akciğer ile ilgili komplikasyonlar gelişti. Bunların 14'ü hemotoraks, 12'si hidrotoraks, 2'si pnomotoraks ve 1'i reno-plevral fistül idi. Bu hastalardan 24'üne (\%1) toraks tüpü uygulandı.
Fistül gelişen hastaya ise açık fistülektomi operasyonu yapılarak toraks tüpünden idrar ekstravazasyonunun kesildiği görüldü.

Bir hastada nefrostomiden gayta gelmesi ile, bir hastada ise nefrostografi sonrası kolona opak madde ekstravazasyonunun görülmesi ile toplam 2 hastada kolon perforasyonu tespit edildi. Bu hastalara primer onarım ve gecici kolostomi uygulandı.

Operasyon esnasında 3 hastada yoğun kanama nedeni ile, operasyon sonrası dönemde ise 5 hastada kanama, 1 hastada piyonefroz, 1 hastada reno-plevral fistül nedeni ile toplam 10 hastada açık operasyona geçildi. Bu hastaların 5 'ine (\%0.22) nefrektomi uygulandı. Operasyon esnasında ve operasyon sonrasında birer hastada kardiyopulmoner nedenlerden dolayı ölüm görüldü.

\section{Tartışma}

Fernström ve Johansson'ın 1976'da, dünyada ilk olarak perkütan yol oluşturarak böbrekten taş aldıklarını bildirmelerinin ardından, Mayo Clinic, Minnesota Üniversitesi, Batı Almanya ve İngiltere'de yapılan çalışmalar sayesinde PNL'nin standart uygulama tekniği geliştirilmiştir (4-7). Bunun neticesinde 1980'li yılların başında dünyada ilk PNL serileri, $1985^{\prime}$ li yıllarda ise ilk geniş PNL serileri yayınlanmaya başlanmıştır (8). Ülkemizde ise ilk PNL uygulaması Aras ve ark. tarafından 1989 yılında bildirilmiş olmasına rağmen, ilk geniş serilerin yayınlanması 2000'li yılları bulmuştur (9). Başlardaki bu yavaş ivmenin aksine özellikle son yıllarda ülkemizde 
de endoüroloji alanında önemli gelişimler yaşanmış ve neticesinde perkütan cerrahi bir çok klinikte başarı ile uygulanır hale gelmiştir.

Literatürde böbrek taşı cerrahisi sonrası 'başarının tanımı' ile ilgili tartışmalar mevcuttur. Günümüzde 4 mm'den küçük, enfeksiyona, ağrıya veya tıkanıklığa neden olmayan taş parçacıkları için CIRF tabiri kullanılmaktadır. illk olarak ESWL sonrası ortaya atılan CIRF tabiri, daha sonraları PNL ve URS sonrasında aynı özellikteki taşlar için de kullanılmaya başlanmıştır (10). CIRF bazı çalışmalarda 'başarı' olarak kabul edilirken, bazı çalışmalarda 'başarısızlık' olarak kabul edilmektedir. Ayrıca CIRF tanımı, genellikle 4 mm'den küçük taşlar için kullanılırken; son çalışmalarda ' 2 mm' boyutu ortaya atılmıştır (11). Böylece muhtemel komplikasyon oranlarının azaltılabileceği öne sürülmüştür. Sonuç olarak, literatürde güvenli bir şekilde geride bırakılabilecek taş boyutu olup olmadığı, var ise bunun kaç mm olacağı konusunda tartışmalar devam etmektedir. Çalışmamızda PNL sonrası sonrası SF veya CIRF varlığı 'başarı', 4 mm'den büyük parçacık varlığı ise 'başarısızlık' olarak kabul edilmiştir.

PNL sonrası başarı oranları taşların sayısına, yerleşimine, kimyasal yapısına ve cerrahın tecrübesine bağlı olarak \%40-\%90 arasında değişmektedir (12). PNL esnasında tam taşsızlık sağlanamamasının temel nedenleri arasında, taşın ya da taş parçalarının ulaşılamayacak bir kalikse kaçması, kanamaya ve uzamış süreye bağlı operasyonun sonlandırılması sayılabilir. Bununla birlikte yanlış cerrahi teknik seçimi, anatomik anormallikler, taş kompozisyonu ve teknik zorlamalar rezidüel taşların sayısını ve boyutunu etkileyebilir (10). Rest (kalıntı) taş fragmanları hastaya ağrı, üriner enfeksiyon, taş büyümesi, obstrüksiyon ve ikincil cerrahi intiyacı gibi çeşitli riskler yüklemektedir. Bu nedenle PNL'de SF sağlanması oldukça önemlidir. Çalışmamızda SF oranı \%65.1, SF ve CIRF toplamı olarak hesaplanan başarı oranı ise \%78.5 idi. Çalışmamızda ayrıca, taş boyutunun artmasının ve taşların multipl kaliks yerleşimli olmasının başarı oranlarını azalttığı görülmüştür.

PNL'de temel amaç en az morbidite ile en fazla taşın temizlenmesidir. PNL minimal invazif bir tedavi yöntemi olarak kabul edilmesinin yanında transfüzyon gerektiren kanama, iç organ yaralanmaları, hidrotoraks, sepsis gibi ağır komplikasyonları içermektedir. CROES Global PNL Çalışma Grubunun 2011 yılında yayınladığı ve PNL komplikasyonlarının değerlendirildiği çok merkezli çalışmada, PNL sonrası genel komplikasyon oranının \%2.5 (1175/5724) olduğu; bunların \%80'inin minör ve \%20'sinin majör komplikasyon olduğu, en sık görülen komplikasyonların ateş ve kanama olduğu bildirilmiştir
(13). Çalışmamızda ise genel komplikasyon oranı \%29.5 tespit edilmiş olup, en sık komplikasyonun kanama olduğu görülmüştür. Serimizdeki komplikasyon oranının literatürden daha yüksek çıkmasının temel nedeni olarak kliniğimizde PNL'nin ağırlıklı olarak asistanlara yaptırılıyor olması düşünülmektedir.

PNL'de iç organ yaralanmaları nadir görülmelerine rağmen oldukça sıkıntılı durumlar oluşturabilmektedir. Literatürde karaciğer, dalak, ince bağırsak ve kolon yaralanmaları bildirilmişse de bunlar arasında en sık yaralanan organ \%0.2 oranı ile kolondur (14). Bizim serimizde de 2 (\%0.09) hastada kolon yaralanması görülmüş olup hastalar primer onarım ve geçici kolostomi ile tedavi edilmişlerdir. Özellikle retrokolon olduğu durumlarda kolon yaralanmasından sakınmak için giriş sırasında daha dikkatli olunmalıdır.

PNL'de akciğer ile ilgili komplikasyonlar genellikle suprakostal girişlerinde görülmektedir. PNL sonrası pnömotoraks, hidrotoraks oranının \%6-\%12 olduğu bildirilmektedir (15). Bizım serimizde de rastladığımız akciğer komplikasyonlarının tamamının suprakostal giriş ile olduğu görülmüştür. Serimizde toplam 227 vakada uygulanan suprakostal girişin 29'unda akciğer ile ilgili komplikasyonların olduğu görülmüştür. Akciğer ile ilgili komplikasyonların çoğunluğu konservatif tedavi ve göğüs tüpü drenajı ile tedavi edilmektedir. Serimizde de hastaların benzer şekilde hastaların tümüne göğüs tüpü tatbik edilmiş olup, sadece bir hastada reno-plevral fistül geliştiği için açık operasyon yapılma gereği duyulmuştur. Üst kalikse yapılacak suprakostal girişlerde özellikle giriş tekniği çok önemlidir. Girişin her aşamasında hastaya derin ekspiryum yaptırılması, daha medialden ve daha dik açı ile girilmesi plevra ve akciğer yaralanma riskini azalttığı düşünülmektedir.

Çalışmamız oldukça yüksek sayıda vaka içermesinin yanında bazı kısıtlılıkları içermektedir. Bunlar arasında çalışmanın geriye dönük olması, rest taşların tespitinde sadece BT değil iVP'nin de kullanılmış olması ve başarı kriteri olarak olarak CIRF grubunun da alınmış olması sayılabilir.

\section{Sonuç}

Artan deneyim ve endoürolojideki gelişmeler sayesinde PNL tüm dünyada olduğu gibi ülkemizde de düşük morbidite ve yüksek başarı ile yaygın bir şekilde uygulanmaktadır.

\section{Kaynaklar}

1. Menon M, Resnick Ml. Urinary Lithiasis: etiology, epidemiyology and pathogenesis. Campell's Urology, Editorin-chief: Alan J. Wein. Sounders, 2007, 9. Edition, 2. Volume, 42. Chapter 
2. Muslumanoglu AY, Binbay M, Yuruk E, ve ark. Updated epidemiologic study of urolithiasis in Turkey. I: Changing characteristics of urolithiasis. Urol Res 2011;39:309-14.

3. Matlaga BR, Assimos DG. Changing indications of open Stone surgery. Urology 2002;59:490-4.

4. Segura JW, Patterson DE, LeRoy AJ, McGough PF, Barrett DM. Percutaneous stone removal of kidney stones: Preliminary report. Mayo Clin Proc 1982;57:615-20.

5. Clayman RV.; Techniques in percutaneous removal of renal calculi. Urol 1984;23:11-9.

6. Alken $P$, Hutschenreiter $G$, Günther $R$, Marberger $M$; Percutaneous stone manuplation. J Urol 1981;125;463-8.

7. Wicham JEA., Kellett MJ: Percutaneous nephrolithotomy. Br J Urol 1981;53:297-302.

8. Segura JW, Patterson DE, LeRoy AJ, et al. Percutaneous removal of kidney stones: review of 1000 cases. J Urol 1985;134:1077-81.

9. Aras N, Kadıoğlu A, Müslümanoğlu AY, Ersay AR. Perkütan nefrolitotomi. Türk Üroloji Dergisi 1989;15:565-72.
10. Delvecchio FC, Preminger GM. Management of residual stones. Urol Clin North Am 2000;27:347-54

11. Raman JD, Bagrodia A, Gupta A, et al. Natural history of residual fragments following percutaneous nephrostolithotomy. J Urol 2009;181:1163-8.

12. Park J, Hong B, Park T, Park HK. Effectiveness of noncontrast computed tomography in evaluation of residual stones after percutaneous nephrolithotomy. J Endourol 2007;21:684-7.

13. Labate G, Modi P, Timoney A, et al. On Behalf Of The Croes Pcnl Study Group. The percutaneous nephrolithotomy global study: classification of complications. J Endourol. 2011;25:1275-80.

14. Yalçın V, Önder AU, Demirkesen O, Önal B, Kalkan M, Kural AR. Böbrek taşlarının tedavisinde perkütan nefrolitotomi. Türk Üroloji Dergisi 2002;28:194-200.

15. Clayman RV, Mcdougall EM, Nakada SY. Endourology of the upper urinary tract: percutaneous renal and ureteral procedures. In: Wals PC, Retik AB, Vaughan EJ, Wein AJ, eds. Campbell's urology. Philadelphia: WB Saunders; 1998;2789-874. 